\title{
ANNEALING OF POLYCRYSTALLINE THIN FILM SILICON SOLAR CELLS IN WATER VAPOUR AT SUB-ATMOSPHERIC PRESSURES
}

\author{
Peter Pikna $^{a, b, *}, V_{\text {lastimil Píc }}^{b}$, Vítězslav Benda $^{a}$, Antonín Fejfar $^{b}$ \\ ${ }^{a}$ Department of Electrotechnology, Czech Technical University, Technicka 2, 16627 Prague, Czech Republic \\ ${ }^{b}$ Institute of Physics, Academy of Sciences of CR, Cukrovarnicka 10, 16253 Prague, Czech Republic \\ * corresponding author: pikna@fzu.cz
}

\begin{abstract}
Thin film polycrystalline silicon (poly-Si) solar cells were annealed in water vapour at pressures below atmospheric pressure. The PN junction of the sample was contacted by measuring probes directly in the pressure chamber filled with steam during passivation. The Suns- $V_{\mathrm{OC}} \operatorname{method}$ and a Lock-in detector were used to monitor the effect of water vapour on $V_{\mathrm{OC}}$ of the solar cell during the whole passivation process (in-situ). The tested temperature of the sample $\left(55-110^{\circ} \mathrm{C}\right)$ was constant during the procedure. The open-circuit voltage of a solar cell at these temperatures is lower than at room temperature. Nevertheless, the voltage response of the solar cell to the light flash used during the Suns- $V_{\mathrm{OC}}$ measurements was well observable. The temperature dependences for multicrystalline wafer-based and polycrystalline thin film solar cells were measured and compared. While no significant improvement to the parameters of the thin film poly-Si solar cells from annealing in water vapour at below-atmospheric pressures has been observed in the past, in-situ observation proved that there was the required sensitivity to changing $V_{\mathrm{OC}}$ at elevated temperatures during the process.
\end{abstract}

KEYWORDS: passivation, water vapour, thin film solar cell, polycrystalline silicon (poly-Si), multicrystalline silicon (m-Si), Suns- $V_{\mathrm{OC}}$.

\section{INTRODUCTION}

The efficiency of a solar cell is directly influenced by the semiconductor material that is used. However, high quality materials tend to be rather expensive, while cheaper materials are of lower quality. One possible way to deal with this issue is to reduce the number of imperfections and defects in the structure of a solar cell. Sufficient photovoltaic efficiency of thin film solar cells in connection with a sufficiently low production price is the key condition for competitiveness on the market dominated by wafer-based solar cells. Plasma hydrogenation is usually used for passivation, i.e., to reduce the electrical activity of recombination centres, e.g., grain boundaries, impurities and crystallographic defects in silicon [1/5]. However, this relatively expensive passivation procedure could be replaced by a cheaper alternative - passivation in water vapour 66]

\section{EXPERIMENTAL}

The use of passivation by water vapour was investigated using thin film silicon solar cells fabricated by CSG Solar AG, Germany. The structure of the solar cell is shown in Fig. 1 9]. These solar cells were placed in a stainless steel pressure chamber filled with deionized water. The chamber was heated to prepare water vapour. Fig. 2 shows the passivation apparatus with the solar cell contacted directly in the pressure chamber. The steam pressure in the chamber was regulated by the temperature of the chamber heater

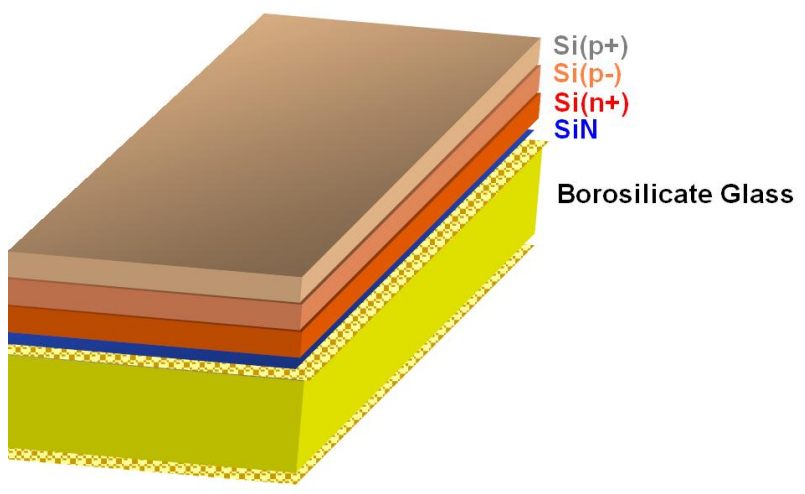

FiguRE 1. Structure of a thin film polycrystalline silicon solar cell fabricated by CSG Solar AG without metallization to allow passivation in water vapour 9 .

according to the water phase diagram [10 12]. The solar cell was heated separately by the pyrolytic Boron Nitride sample heater [13] supplied by wiring passing into the chamber through the feedthroughs. The temperature of the sample was measured using a coaxial thermocouple 13 .

The temperature of the cell was at all times kept around $10^{\circ} \mathrm{C}$ higher than the temperature of the steam, in order to prevent it condensing on the sample and to ensure passivation strictly in vapour. The steam pressures ranged from 0.01 to $0.1 \mathrm{MPa}$. The performance of water vapour passivation was measured by the Suns- $V_{\text {OC }}$ method and a Lock-in detector during the process every 15 minutes for 2 hours. Open-circuit 


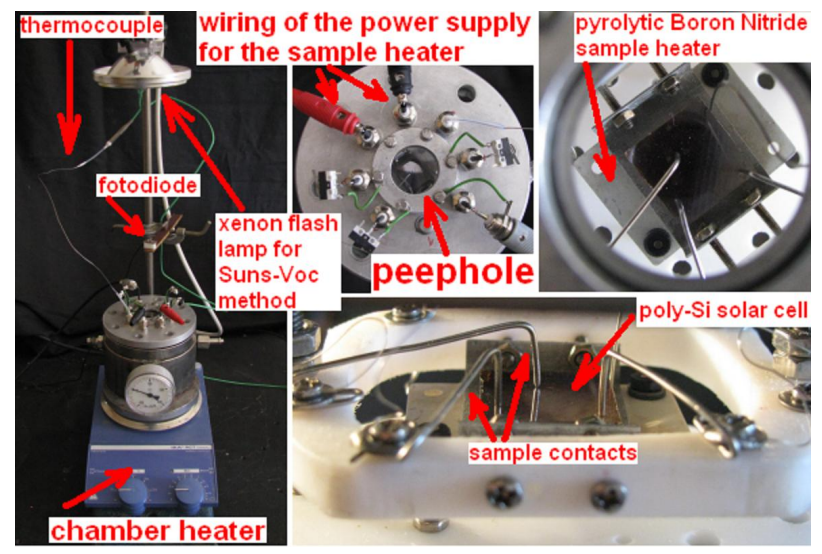

Figure 2. Apparatus comprising the stainless steel pressure chamber, the heater, the xenon flash lamp, the thermocouple, the pyrolytic Boron Nitride sample heater, and stainless steel probes to contact the investigated thin film poly-Si solar cell used for investigating water vapour passivation.

voltage $V_{\mathrm{OC}}$ is commonly used as a silicon quality factor. The higher the $V_{\mathrm{OC}}$, the lower the concentration of defects [3]. This key parameter was measured at light intensity $1000 \mathrm{~W} / \mathrm{m}^{2}=1 \mathrm{SUN}$ for the Suns- $V_{\mathrm{OC}}$ method (a xenon flash used as a light source) and at the light intensity of a white LED determined only approximately to be around $1000 \mathrm{~W} / \mathrm{m}^{2}$ for the Lock-in detector.

\section{SUNS- $V_{\text {OC }}$ METHOD}

The principle of the Suns- $V_{\mathrm{OC}}$ method is based on a light flash about 10 times longer than the lifetime of the charge carriers in the investigated semiconductor [14. Free charge carriers are generated in the semiconductor by absorption of light, and it takes some time - the lifetime of the free charge carrier to recombine with the oppositely charged carrier. The decrease in light intensity during the light flash is a slow process from the point of view of the generated charge carriers. A quasi-steady state of the charge carrier concentration can therefore be assumed in every moment of the measurement during the light decay.

Two parameters - the light intensity, and the corresponding $V_{\mathrm{OC}}$ - are measured in time, as shown in Fig. 3. They are also presented in Fig. 4 for better understanding, where the data is needed for the Suns- $V_{\text {OC }}$ measurement in comparison with a common current-voltage measurement.

In principle, Suns- $V_{\mathrm{OC}}$ measurements can be understood as a sequence of ordinary current-voltage measurements at different light intensities (from $100 \mathrm{~W} / \mathrm{m}^{2}$ to $1000 \mathrm{~W} / \mathrm{m}^{2}$ in Fig. 4, where only $V_{\mathrm{OC}}$ is noted at the corresponding light intensities. It is very important to know that the light intensity and the generated solar cell short-circuit current $I_{\mathrm{SC}}$ are linearly proportional. If some value of the current generated by the solar cell at the corresponding light intensity is known, e.g., $I_{\mathrm{SC}}$ at $1000 \mathrm{~W} / \mathrm{m}^{2}$ measured at a com-

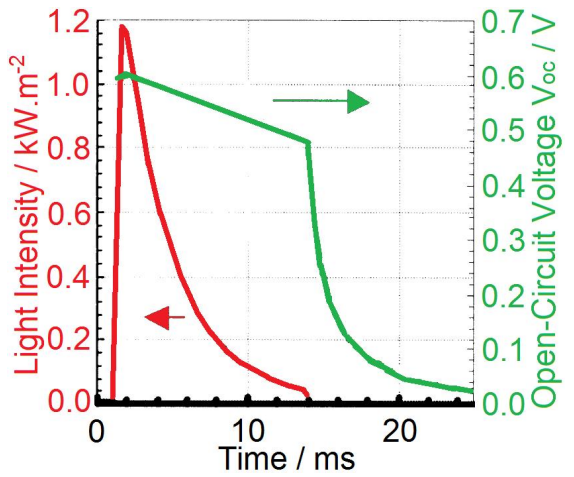

Figure 3 . Suns- $V_{\mathrm{OC}}$ measurement: the decrease in light intensity and the corresponding open-circuit voltage $V_{\mathrm{OC}}$ of the solar cell in time [15].

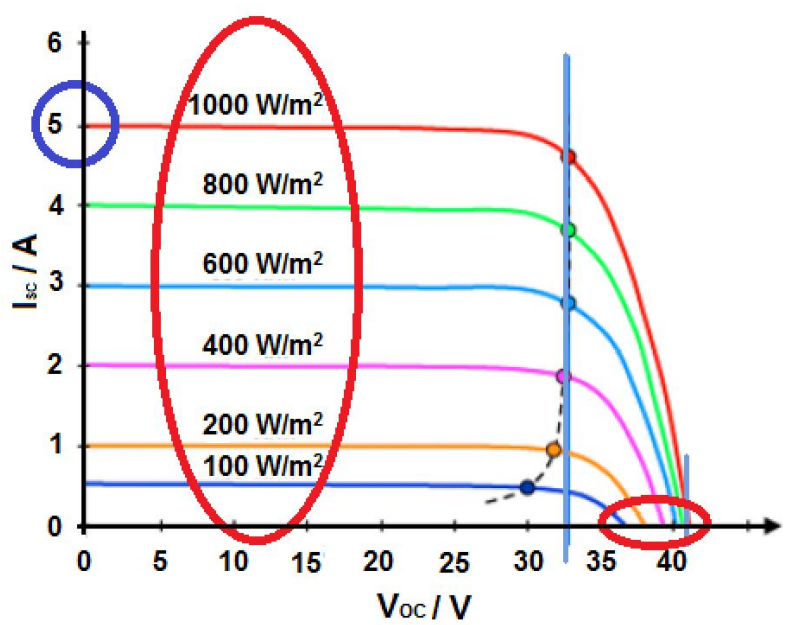

FiguRE 4. Explanation of the Suns- $V_{\text {OC }}$ method: two parameters - the light intensity and the corresponding open-circuit voltage marked by the red ellipses - are measured during the Suns-Voc measurement, and one parameter - the short-circuit current $I_{\mathrm{SC}}$ at light intensity of $1000 \mathrm{~W} / \mathrm{m}^{2}$ (blue circle) - is needed from some other measurement, e.g., a common currentvoltage measurement, to recalculate the detected light intensity of the flash into $I_{\mathrm{SC}}$ of the solar cell [16].

mon current-voltage $(I-V)$ measurement, any light intensity illuminating the solar cell can be recalculated to the current generated by the solar cell, as is done to compare a Suns- $V_{\text {OC }}$ measurement with a common $I-V$ measurement, see Fig. 5 This picture consists of two graphs. The graph on the left-hand side presents a measurement of the light intensity illuminating a solar cell and the corresponding $V_{\mathrm{OC}}$ of the solar cell during a light flash around $14 \mathrm{~ms}$ in duration. The graph on the right-hand side of the picture shows the current-voltage curve calculated from the data measured by the Suns- $V_{\text {OC }}$ method, and also explains the differences between this Suns- $V_{\text {OC }}$ current-voltage characteristic and the $I-V$ curve of the same solar cell measured in the common way. According to the $I-V$ curves presented here, the Suns- $V_{\text {OC }}$ measurement gives better results (efficiency and fill factor). The 

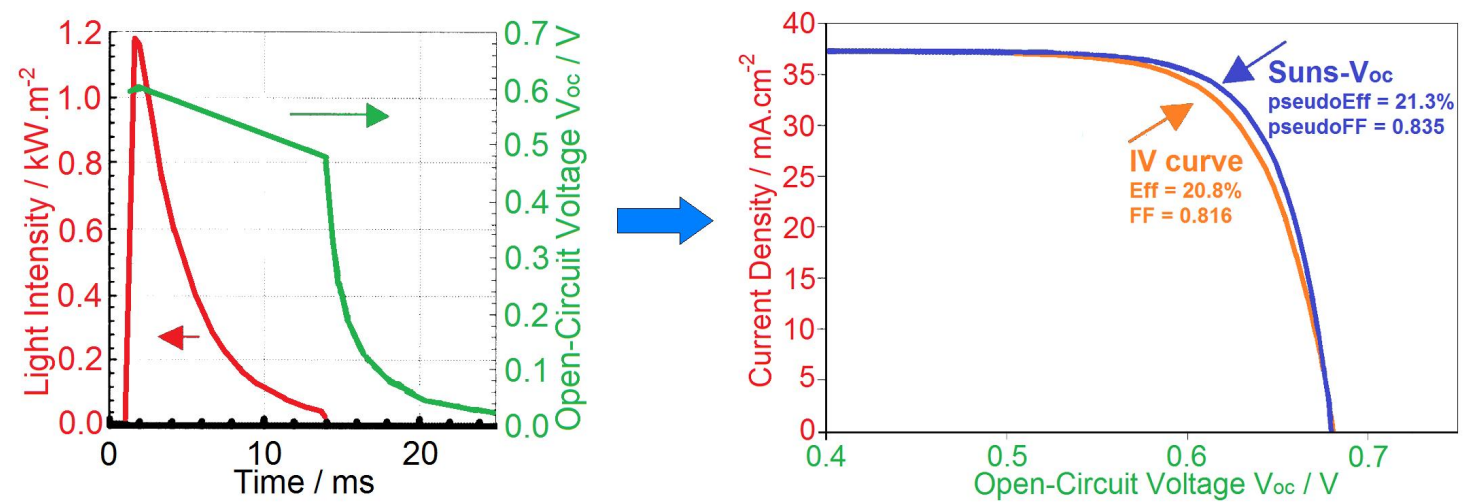

Figure 5. Creation of a Suns- $V_{\mathrm{OC}}$ current-voltage characteristic from the measured light intensity and the corresponding $V_{\mathrm{OC}}$. Comparison of a Suns- $V_{\mathrm{OC}}$ measurement with a current-voltage characteristic of the same solar cell measured in the common way 15 .

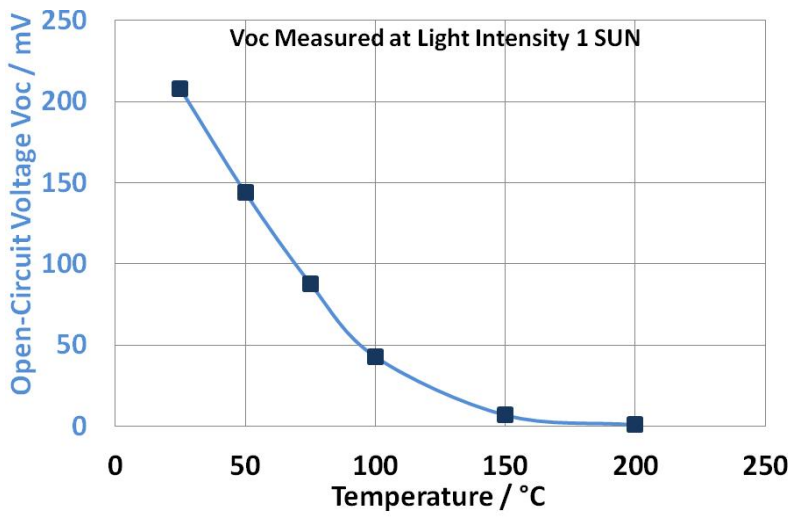

FiguRE 6. Temperature dependence of open-circuit voltage $V_{\mathrm{OC}}$ for a tested non-passivated thin film polycrystalline silicon solar cell.

reason is that the Suns- $V_{\text {OC }}$ method omits the influence of the series resistance of the solar cell, because no current is measured, just voltage. An advantage of this method is that no solar cell metallization is needed, just a pn junction. A comparison of the Suns$V_{\mathrm{OC}}$ measurement performed before the metallization step (deposition of metal electrodes) and a common $I-V$ curve measured after metallization provides information about the quality of this manufacturing procedure.

\section{LOCK-IN DETECTOR}

A MODEL SR830 DSP Lock-in detector was used to measure the open-circuit voltage generated by the tested solar cell during passivation. The open-circuit voltage $V_{\mathrm{OC}}$ of a solar cell decreases as its temperature increases. This is presented in Fig. 6 for a tested nonpassivated thin film polycrystalline silicon solar cell. This data was measured by the Suns- $V_{\text {OC }}$ method, $V_{\text {OC }}$ was measured at light intensity $1000 \mathrm{~W} / \mathrm{m}^{2}$ of a xenon flash lamp.

According to the measured data, $V_{\mathrm{OC}}$ becomes comparable with/lower than the parasitic thermo- electrical voltage $\mathrm{Vth}$ at higher temperatures $\left(V_{\mathrm{OC}} \approx\right.$ $5 \mathrm{mV}, V_{\mathrm{th}} \approx 23 \mathrm{mV}$ at $\left.150^{\circ} \mathrm{C}\right)$. To measure $V_{\mathrm{OC}}$ at elevated temperatures, the generated photovoltage signal $V_{\text {OC }}$ has to be amplified or measured selectively by a Lock-in detector. The basic idea of this measurement is that the Lock-in detector supplies a light source (white LED in our case) with a specific frequency $(70 \mathrm{~Hz}$ in our case). Simultaneously, the same Lock-in detector measures the $V_{\mathrm{OC}}$ of the investigated solar cell. The measured $V_{\mathrm{OC}}$ has an alternating (AC) character with the same frequency as the light source $(70 \mathrm{~Hz})$. The photogenerated AC voltage is separated from the parasitic thermo-electrical voltage of direct (DC) character, and also from any other parasitic signals by the Lock-in detector measuring only signals with the same frequency as it generates $(70 \mathrm{~Hz}$ of the white LED). Selective measurement of $V_{\text {OC }}$ for a tested solar cell can be done this way, and even very small signals that normally vanish in noise can be detected with high accuracy.

\section{RESUlts AND Discussions}

The development of the open-circuit voltage of a solar cell passivated at different temperatures $\left(55-110^{\circ} \mathrm{C}\right)$ and steam pressures $(0.01-0.1 \mathrm{MPa})$ is shown in Fig. 7 These investigations were realized by the Suns- $V_{\mathrm{OC}}$ method. According to photovoltaic theory, average $V_{\text {OC }}$ decreases with increasing temperature. No clear trend of $V_{\mathrm{OC}}$ in time at particular temperatures was observed, and previous expectations of increasing $V_{\mathrm{OC}}$ during annealing due to passivation of solar cell defects were not fulfilled. It is assumed that the changes in $V_{\mathrm{OC}}$ in time are probably caused by instability of the contacting probes.

Some details about the process should be noted in order to provide a picture of the complexity of the experiments that were performed, and to discuss possible reasons for the negative results that were obtained. $V_{\mathrm{OC}}$ was measured at sample passivation temperatures higher than room temperature $\left(55-110^{\circ} \mathrm{C}\right)$. The 


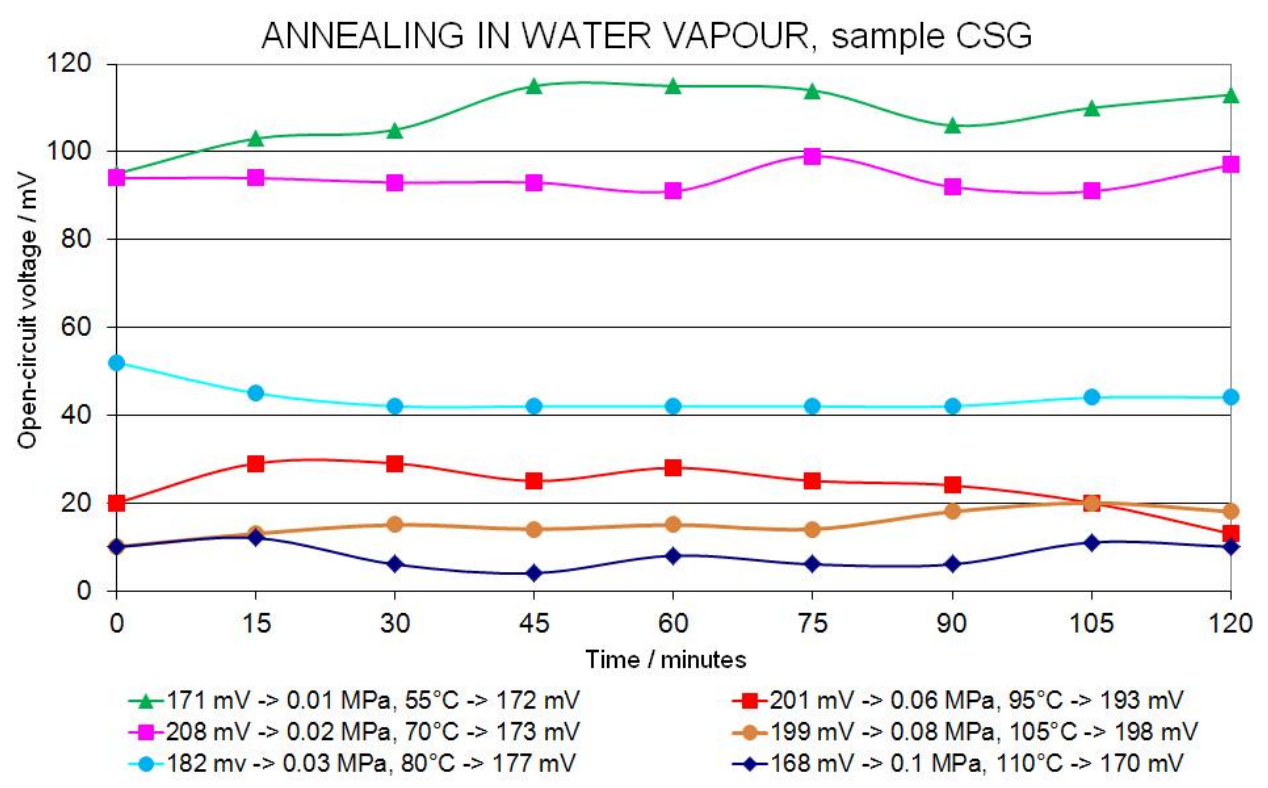

Figure 7. Open-circuit voltage $V_{\mathrm{OC}}$ of the thin film poly-Si solar cell CSG measured in time at light intensity $1000 \mathrm{~W} / \mathrm{m}^{2}$ for different temperatures by the Suns- $V_{\mathrm{OC}}$ method; legend for the measurements: $V_{\mathrm{OC}}$ at room temperature before passivation (e.g., $171 \mathrm{mV}$ ), water vapour pressure (e.g., 0.01 MPa), sample temperature (e.g., $55^{\circ} \mathrm{C}$ ) during passivation, and $V_{\mathrm{OC}}$ at room temperature after passivation (e.g., $172 \mathrm{mV}$ ). Voltage $V_{\mathrm{OC}}$ at room temperature is not depicted in the graph. It was measured at light intensity 1 SUN by the Suns-Voc method, as during annealing.

intensity of the measured signal was therefore limited, see Fig. 6. The thermal conductivity of the stainless steel chamber is relatively poor. Due to the non-homogeneous temperature distribution in particular parts of the chamber, the temperature gradient changed in time. The influence of the thermo-electrical voltage should therefore also be taken into account.

The thermo-electric voltage can be explained in the following way. When two different metals are connected in two points, and the temperature of these connections is different, the electrical voltage can be measured as the difference in the electrical potential at these two places [17.

A MODEL SR830 DSP Lock-in detector with $70 \mathrm{~Hz}$ flashing frequency of the white LED was used to separate the "AC $V_{\mathrm{OC}}$ " alternating part of the signal and the "DC $V_{\mathrm{OC}}$ " direct part (thermo-electrical voltage and illumination background). The "AC $V_{\mathrm{OC}}$ " part of the signal (bold curves) measured by the Lock-in detector, and the "DC $V_{\mathrm{OC}}$ " part of the signal, measured by Suns- $V_{\mathrm{OC}}$ purged of parasitic thermo-electrical voltage (fine curves), are shown in Fig. 8

The open-circuit voltage of a solar cell can be measured in direct (DC) mode under constant illumination, e.g., by the Suns- $V_{\mathrm{OC}}$ method, or under alternating (AC) light, e.g., by a Lock-in detector. The measurement of $V_{\mathrm{OC}}$ under a slow decaying light flash used for the Suns- $V_{\mathrm{OC}}$ method can be understood as a sequence of many separate $V_{\mathrm{OC}}$ measurements under smaller and smaller constant light intensities (DC mode). If the decay of the light intensity during the light flash is appropriately slow, the semiconductor material has enough time to approach the equilibrium state - a balance between generated and recombined free charge carriers, electrons and holes, and this measurement is called a quasi-steady-state measurement. Suns- $V_{\mathrm{OC}}$ measurements are quasi-steady state measurements, and the appropriate duration of the light flash is around $10 \mathrm{~ms}$ for polycrystalline silicon.

Another way to measure the $V_{\mathrm{OC}}$ of a solar cell is under a sequence of relatively fast flashes (duration in the range of $\mu \mathrm{s}$ ). The solar cell generates $V_{\mathrm{OC}}$ with the same frequency as the frequency of the fast light flashes. The solar cell generates AC voltage. To compare the $V_{\mathrm{OC}}$ of a solar cell measured as a quasi-steady state measurement (Suns- $V_{\mathrm{OC}}$ method) and as an AC measurement under a sequence of fast light flashes, it is necessary to transfer the $\mathrm{AC}$ voltage to $\mathrm{DC}$, or vice versa. In principle, this is similar to comparing the voltage measured in an electricity network (230 VAC) and the DC voltage of some accumulator. In order to compare $\mathrm{AC}$ and $\mathrm{DC}$ voltage, it is necessary to calculate the effective $\mathrm{AC}$ voltage, see [18].

A comparison between the effective alternating part of $V_{\mathrm{OC}}$ measured by a Lock-in detector and a direct signal measured by the Suns- $V_{\mathrm{OC}}$ method purged of parasitic DC signals (thermo-electrical voltage) was performed on the basis of the following recalculation, using $V_{\mathrm{OC}}$ measured at room temperature. The opencircuit voltage of the sample measured under a slow light flash at room temperature (RT) was $201 \mathrm{mV}$, and it corresponded to the alternating voltage measured by a $60.7 \mathrm{mV}$ Lock-in detector, also at RT. All data measured by the Lock-in detector during passivation was therefore multiplied by factor $F$ to compare them with the reference "DC $V_{\mathrm{OC}}$ " of the non-passivated 


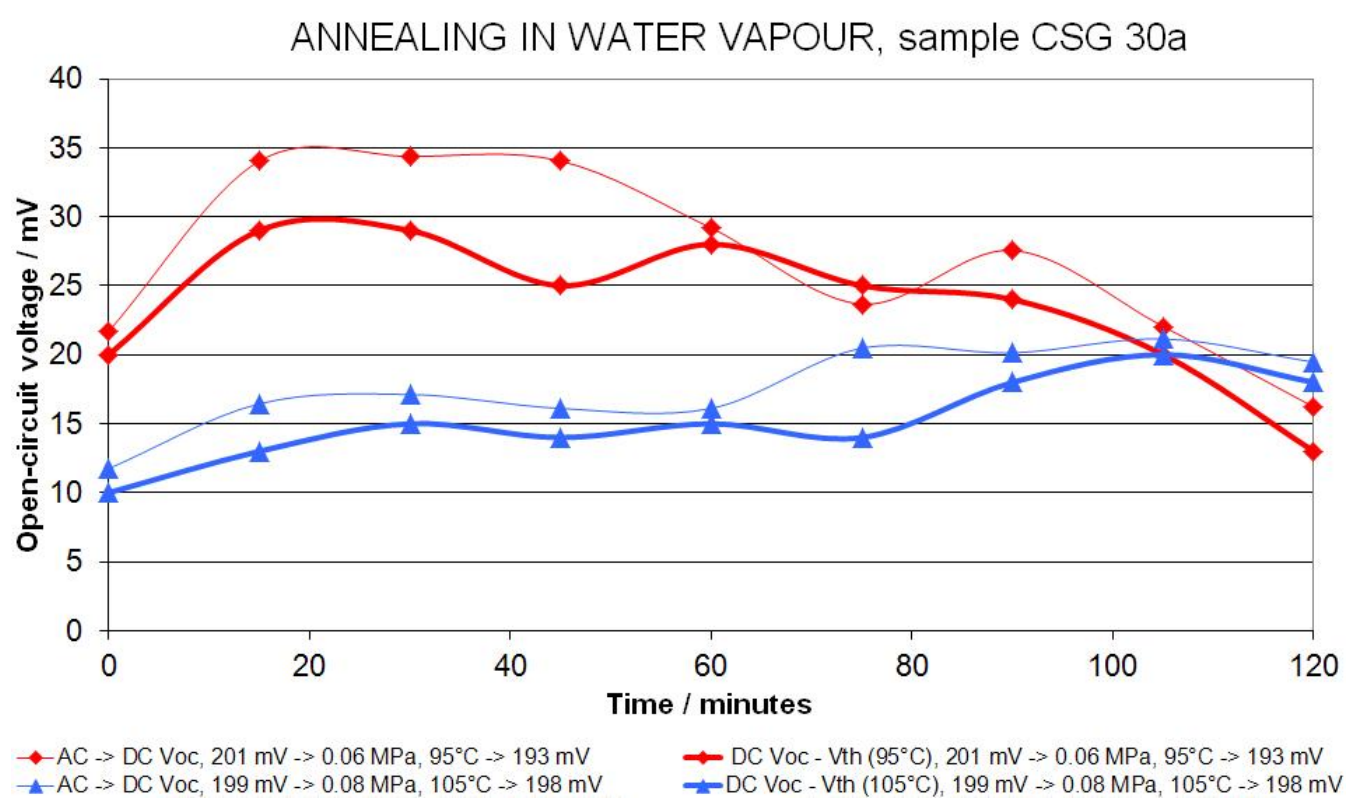

FiguRE 8. Annealing the thin film solar cell (sample CSG 30a) in water vapour at vapour pressures 0.06 and $0.08 \mathrm{MPa}$. The temperature of the sample was $95^{\circ} \mathrm{C}$ (for $0.06 \mathrm{MPa}$ ) and $105^{\circ} \mathrm{C}$ (for $0.08 \mathrm{MPa}$ ). The bold curves represent data measured by the Suns- $V_{\mathrm{OC}}$ method purged of the parasitic thermo-electrical voltage Vth. The fine curves are data measured by the Lock-in detector, subsequently recalculated into DC voltage according to formula (1). Legend: $V_{\mathrm{OC}}$ at room temperature before passivation (e.g., $201 \mathrm{mV}$ ), water vapour pressure (e.g., $\left.0.06 \mathrm{MPa}\right)$ and sample temperature (e.g., $95^{\circ} \mathrm{C}$ ) during passivation and $V_{\mathrm{OC}}$ at room temperature after passivation (e.g., $\left.193 \mathrm{mV}\right)$. Voltage $V_{\mathrm{OC}}$ at room temperature is not depicted in the graph. It was measured at light intensity 1 SUN by the Suns-Voc method, as during annealing.

solar cell at RT equal to $201 \mathrm{mV}$, see below:

$$
F=\frac{\mathrm{DC} V_{\mathrm{OC}}}{\mathrm{AC} V_{\mathrm{OC}}}=\frac{201 \mathrm{mV}}{60.7 \mathrm{mV}}=3.31
$$

This recalculation allowed a comparison between "DC $V_{\text {OC }}$ " data measured by Suns- $V_{\text {OC }}$ and "AC $V_{\text {OC }}$ " data measured by the Lock-in detector. Factor $F=3.31$ allowed to omit some inconsistences of the measurements performed by the Lock-in detector and the Suns- $V_{\mathrm{OC}}$ method. The Suns- $V_{\mathrm{OC}}$ measurement used a xenon flash lamp, but the Lock-in detector used a white LED; the intensity and the spectra of the light sources were different - the Lock-in detector expected a sinus-shaped detected signal, but the white LED flashed with a rectangle shape function

All these discrepancies are included in factor $\mathrm{F}$. Data measured by the Suns- $V_{\text {OC }}$ method and data from the Lock-in detector recalculated on the basis of the formula presented above are shown below. Fine curves represent data measured by the Lock-in detector, and the results were recalculated according to formula (1). Bold curves are data measured by the Suns- $V_{\text {OC }}$ method. Thermo-electrical voltage Vth at an appropriate temperature was subtracted from them. The Vth data was measured in the dark, directly on the contacts used for $V_{\mathrm{OC}}$ measurements. The red curves are correlated, with the exception of some points; there is an even better correlation between the blue curves.

The discrepancy between the "AC $V_{\mathrm{OC}}$ " and "DC $V_{\mathrm{OC}}$ " data is probably due to changes in the thermo-electrical voltage in time, or mechanical instability of the contacts. Another explanation could be an impact of the illumination background. These imperfections should be removed for future experiments, and then a more exact determination of $V_{\mathrm{OC}}$ would be approached. Better correlation of "AC $V_{\mathrm{OC}}$ " and "DC $V_{\text {OC" }}$ could then be expected.

Temperature dependences of the open-circuit voltage for a polycrystalline thin film solar cell and a multicrystalline wafer-based solar cell are shown in Fig. 9. Thermo-electrical voltage Vth at different temperatures was measured for both solar cell types (green curves).

Curves with triangles correspond to the multi-Si wafer-based solar cell, and curves with points represent the poly-Si thin film data. The blue curves represent data measured by the Lock-in detector recalculated on the basis of formula (1) and the red data are from the Suns- $V_{\mathrm{OC}}$ method including Vth.

The results from measurements of $V_{\mathrm{OC}}$ and $\mathrm{Vth}$ for multi-Si and poly-Si solar cells are summarized in Table 1. The $V_{\mathrm{OC}}$ data at room temperatures, the $V_{\text {OC }}$ decrease at increasing temperature in unit $\mathrm{mV} /{ }^{\circ} \mathrm{C}$ and the relative expression in unit $\% /{ }^{\circ} \mathrm{C}$ and also the thermo-electrical voltage at $150{ }^{\circ} \mathrm{C}$ for both solar cell types provide a comparison of the different behaviour of thin film and wafer-based solar cells. The $V_{\mathrm{OC}}$ decrease at increasing temperature is stronger for polySi than for multi-Si for both types of measurements (Suns- $V_{\text {OC }}$, and by the Lock-in detector). However, stronger $V_{\mathrm{OC}}$ temperature dependence was expected 


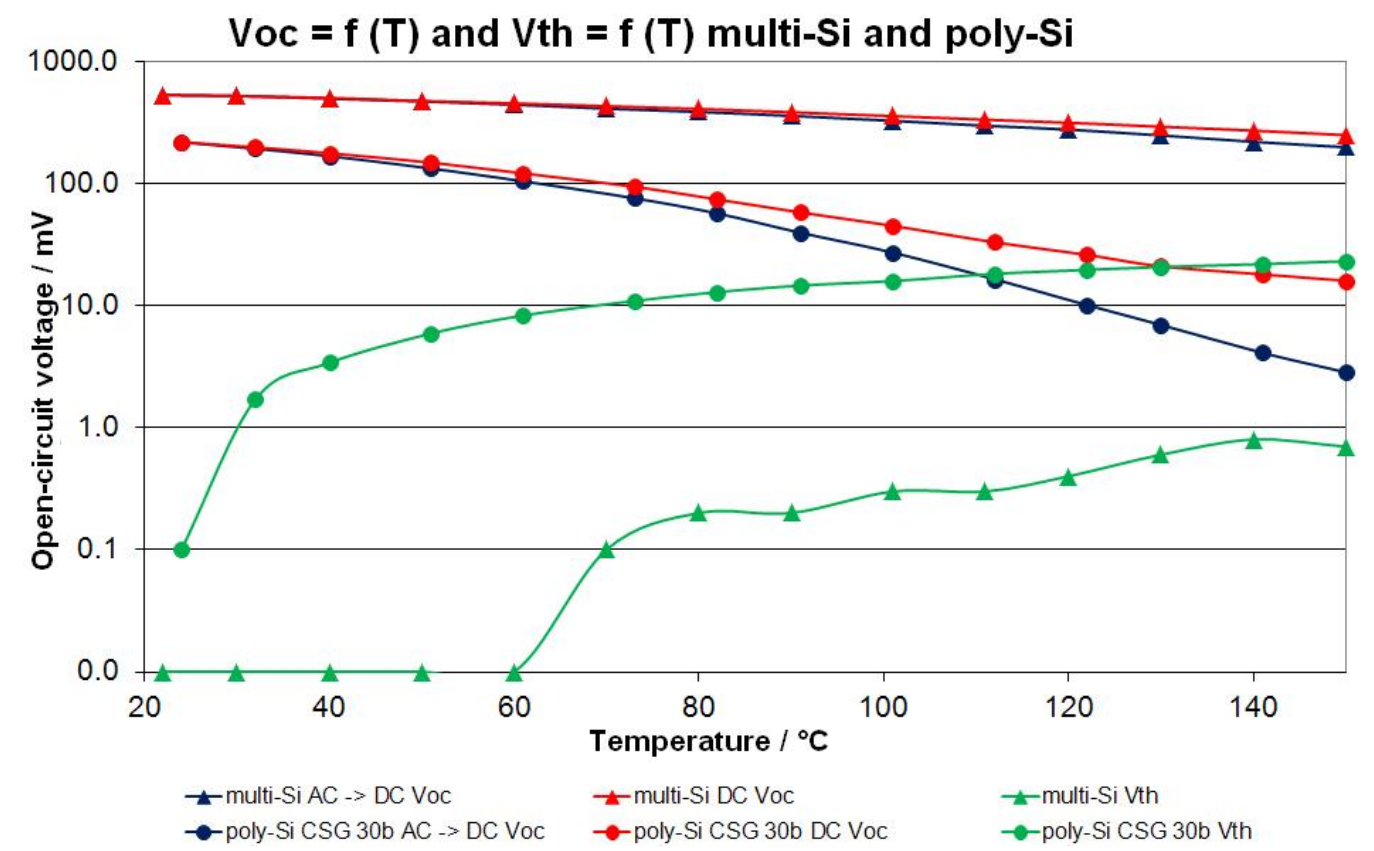

Figure 9. Temperature dependences of $V_{\mathrm{OC}}$ for multicrystalline wafer-based (triangles) and polycrystalline thin film (points) solar cells. Red curves represent data measured by the Suns- $V_{\mathrm{OC}}$ method, including the thermo-electrical voltage; blue curves represent data measured by the Lock-in detector recalculated on the basis of formula (1). The green curves are measurements of thermo-electrical voltage. The "DC $V_{\mathrm{OC}}$ " Suns- $V_{\mathrm{OC}}$ measurements were realized at light intensity $1000 \mathrm{~W} / \mathrm{m}^{2}$ (xenon flash lamp). The light intensity during measurements performed by the Lock-in detector was around 1 SUN (white LED).

\begin{tabular}{ccccc}
\hline Solar cell & $\begin{array}{c}V_{\mathrm{OC}}(\mathrm{mV}) \\
\left(23{ }^{\circ} \mathrm{C}\right)\end{array}$ & $\begin{array}{c}\mathrm{d} V_{\mathrm{OC}} / \mathrm{d} T \\
\left(\mathrm{mV} /{ }^{\circ} \mathrm{C}\right)\end{array}$ & $\begin{array}{c}\mathrm{d} V_{\mathrm{OC}} / V_{\mathrm{OC}} \mathrm{d} T\left(\% /{ }^{\circ} \mathrm{C}\right) \\
\left(23{ }^{\circ} \mathrm{C}\right)\end{array}$ & $\begin{array}{c}V_{\mathrm{th}}(\mathrm{mV}) \\
\left(150^{\circ} \mathrm{C}\right)\end{array}$ \\
\hline Multi-Si AC $V_{\mathrm{OC}}$ & 531 & 2.8 & 0.5 & 0.7 \\
Multi-Si DC $V_{\mathrm{OC}}$ & 531 & 2.3 & 0.4 & 0.7 \\
\hline Poly-Si AC $V_{\mathrm{OC}}$ & 218 & 3.2 & 1.5 & 23.1 \\
Poly-Si DC $V_{\mathrm{OC}}$ & 218 & 2.6 & 1.2 & 23.1 \\
\hline
\end{tabular}

TABLE 1. Overview of $V_{\mathrm{OC}}$ at room temperature, $\mathrm{d} V_{\mathrm{OC}} / \mathrm{d} T, \mathrm{~d} V_{\mathrm{OC}} / V_{\mathrm{OC}} \mathrm{d} T$ and thermo-electrical voltage at $150{ }^{\circ} \mathrm{C}$ for multicrystalline and polycrystalline solar cells.

from the wafer-based solar cell type. The measured thermo-electrical voltage was significantly different for poly-Si and multi-Si. While Vth of the wafer-based solar cell was less than $1 \mathrm{mV}$ at $150^{\circ} \mathrm{C}$, the thin film cell approached more than $23 \mathrm{mV}$ of Vth. This big difference could be explained by an influence from the borofloat glass substrate (thermal insulator) used for poly-Si. The temperature gradients were probably bigger in this case.

\section{Conclusions}

Polycrystalline silicon thin film solar cells were annealed in water vapour to improve their quality by passivation, in other words by de-activating the recombination centres. The slight improvement in $V_{\mathrm{OC}}$ detected in some cases is more likely to be a measurement inaccuracy than a real improvement. The tested pressure range was $0.01-0.1 \mathrm{MPa}$, and the sample temperature ranged from 55 to $110^{\circ} \mathrm{C}$. In spite of the elevated temperatures, the open-circuit voltage
$V_{\mathrm{OC}}$ was well detectable by the Suns- $V_{\mathrm{OC}}$ method and when using the Lock-in detector. Since no significant improvement was observed in the range of sub-atmospheric pressures, our next experiments will be focused on the more promising supra-atmospheric pressures of water vapour. A comparison of the temperature dependences for thin film poly-Si solar cells and wafer-based multi-Si solar cells has been given. All investigations of water vapour passivation were realized using an in-situ setup: the changing $V_{\mathrm{OC}}$ of the solar cell was measured directly during annealing in steam. An advantage of this approach is elimination of a time as a passivation parameter. Therefore, only a steam pressure and a temperature of the process have to be optimised.

\section{ACKNowledgements}

This research work was supported by SGS grant number SGS13/072/OHK3/1T/13, and by projects AV CR M100101216, MPO Moremit FR-TI2/736 and MSMT LNSM. 


\section{REFERENCES}

[1] B. Gorka, Hydrogen Passivation of Polycrystalline Si Thin Film Solar Cells, PhD thesis, Technische Universität Berlin, 2010.

[2] L. Carnel, I. Gordon, K. Van Nieuwenhuysen, D. Van Gestel, G. Beaucarne, and J. Poortmans, Defect passivation in chemical vapour deposited fine-grained polycrystalline silicon by plasma hydrogenation, Thin Solid Films, 487, pp. 147-151, 2005, DOI:10.1016/j.tsf.2005.01.081

[3] L. Carnel, I. Gordon, D. Van Gestel, K. Van Nieuwenhuysen, G. Agostinelli, G. Beaucarne, and J. Poortmans, Thin-film polycrystalline silicon solar cells on ceramic substrates with a Voc above $500 \mathrm{mV}$, Thin Solid Films, 511-512, pp. 21-25, 2006, DOI:10.1016/j.tsf.2005.12.069

[4] B. Gorka, B. Rau, P. Dogan, C. Becker, F. Ruske, S. Gall, and B. Rech, Influence of Hydrogen Plasma on the Defect Passivation of Polycrystalline Si Thin Film Solar Cells, Plasma Processes and Polymers, 6, pp. S36-S40, 2009, DOI:10.1002/ppap.200930202

[5] C. H. Seager, D. S. Ginley: Passivation of grain boundaries in polycrystalline silicon: Applied Physics Letters 34(5), 1979, DOI:10.1063/1.90779

[6] T. Sameshima, H. Hayasaka, M. Maki, A. Masuda, T. Matsui, and M. Kondo: Defect Reduction in Polycrystalline Silicon Thin Films by Heat Treatment with High-Pressure H2O Vapor, Jpn. J. Appl. Phys., 46, pp. 1286-1289, 2007, DOI:10.1143/JJAP.46.1286

[7] S. Honda, T. Mates, B. Rezek, A. Fejfar, J. Kocka: Microscopic study of the $\mathrm{H} 2 \mathrm{O}$ vapor treatment of the silicon grain boundaries, Journal of Non-Crystalline Solids 354, pp. 2310-2313, 2008, DOI:10.1016/j.jnoncrysol.2007.09.107

[8] S. Honda, A. Fejfar, J. Kocka, T. Yamazaki, A. Ogane, Y. Uraoka, T. Fuyuki: Annealing in water vapor as a new method for improvement of silicon thin film properties, Journal of Non-Crystalline Solids 352, pp. 955-958, 2006, DOI:10.1016/j.jnoncrysol.2006.01.061

[9] M. J. Keevers, T. L. Young, U. Schubert, M. A. Green: 10\% Efficient CSG Minimodules, 22nd European Photovoltaic Solar Energy Conference, Milan, Italy, pp. 1783-1790, 2007.

[10] http://www1.lsbu.ac.uk/water/phase.html [2014-07-20].

[11] http://ergodic.ugr.es/termo/lecciones/water1. html [2014-07-20].

[12] http://en.wikipedia.org/wiki/Phase_diagram\# mediaviewer/File:Phase_diagram_of_water.svg [2014-07-20].

[13] http://www.tectra.de/heater.htm [2014-07-20].

[14] R. Sinton: User Manual to Photoconductance Lifetime Tester and Optional Suns-Voc Stage, http://www. sintonconsulting.com [2014-07-20].

[15] R. Sinton, A. Cuevas: A Quasi-Steady-State OpenCircuit Voltage Method for Solar Cell Characterization, 16th European Photovoltaic Solar Energy Conference, Glasgow, United Kingdom, 2000.

[16] H. Schmidt, B. Burger, U. Bussemas, S. Elies: How fast does an MPP tracker really need to be? 24th European Photovoltaic Solar Energy Conference, Hamburg, Germany, 2009.

[17] R. M. Park, R. M. Carroll, P. Bliss, G. W. Burns, R. R. Desmaris, F. B. Hall, M. B. Herzkovitz, D. MacKenzie, E. F. McGuire, R. P. Reed, L. L. Sparks, T. P. Wang, Manual on the Use of Thermocouples in Temperature Measurement, Fourth Edition, ISBN: 0-8031-1466-4, 1993.

[18] N. N. Bhargava, D. C. Kulshreshtha, S. C. Gupta, Basic Electronics and Linear Circuits, Tata McGrawHill Education, ISBN: 0-07-451965-4, 1984. 